\title{
Rapidly-growing pseudoangiomatous stroma hyperplasia (PASH) causing bilateral gigantomastia in a 15-year-old patient
}

\author{
Maarten Vijverberg $^{1}$ (1) $\cdot$ Henriette Kroese-Deutman ${ }^{1} \cdot$ Carla Meeuwis $^{2} \cdot$ Robert Kornegoor $^{3}$ \\ Received: 23 February 2019 / Accepted: 9 July 2019 / Published online: 14 August 2019 \\ (C) The Author(s) 2019
}

\begin{abstract}
A 15-year-old female patient presented to our clinic with rapidly-growing breasts, causing her back and neck pain, mastalgia, and unwanted attention at school. Clinical evaluation showed bilateral enlarged breasts with multiple palpable tumors. Her height and body weight were $1.76 \mathrm{~m}$ and $54 \mathrm{~kg}$, respectively. Both ultrasound and magnetic resonance imaging (MRI) were conducted. Histological biopsies showed pseudoangiomatous stroma hyperplasia (PASH). Bilateral diffuse multiple tumors leading to massive bilateral breast enlargement are rare, especially in pediatric patients. To the best of our knowledge, all previous reported cases were patients of 29 years old or older. We present the evaluation and treatment in a rare case of multiple PASH causing bilateral gigantomastia in an adolescent patient.

Level of evidence: Level V, therapeutic study.
\end{abstract}

Keywords Gigantomastia · PASH · Breast reduction · Bilateral breast hypertrophy.

\section{Introduction}

Gigantomastia is a rare condition defined by diffuse extreme bilateral breast growth. Complaints like neck or back pain and unwanted social attention could be both physically and psychosocially disabling. It is mostly associated with excessive body weight. Other causes are pregnancy or puberty, which is thought to be caused by hypersensitivity of breast tissue to circulating hormones or an excess of circulating hormones [1]. Different classifications of gigantomastia have been proposed. We have used the classification by Dafydd et al., proposing breast tissue that contributes $3 \%$ or more to the patient's body weight [2].

Level of evidence: Level V, therapeutic study.

Maarten Vijverberg

maarten.vijverberg@radboudumc.nl

$1 \quad$ Department of Plastic and Reconstructive Surgery, Rijnstate Hospital, Wagnerlaan 55, 6815 AD Arnhem, the Netherlands

2 Department of Radiology, Rijnstate Hospital, Wagnerlaan 55, 6815 AD Arnhem, the Netherlands

3 Department of Pathology, Rijnstate Hospital, Wagnerlaan 55, 6815 AD Arnhem, the Netherlands
When gigantomastia occurs in younger patients, multidisciplinary approach is important in guiding the patient through the diagnostic and treatment process. Surgeons, radiologists, pathologists, and endocrinologist all play their part. This provides a more holistic approach to the patient.

Pseudoangiomatous stromal hyperplasia (PASH) is a benign proliferation breast stroma cells, characterized by anastomosing slit-like spaces in fibrous tissue which are present within as well as between breast lobules. Often, spindle stromal cells are present as margins of these spaces, simulating endothelial cells [3,4]. The diagnosis of PASH relies on the histological examination of biopsied material or excised lesion. It can present in a various range of severity, from microscopic finding to palpable mass. Ultimately, this could lead to enlargement of the breasts.

Although PASH is not associated with (pre)malignancy, surgery may be indicated to relieve symptoms associated with gigantomastia and prevent further growth. Treatment options include breast reduction surgery or mastectomy with implant reconstruction. Breast reduction surgery is considered the treatment of choice but also mastectomy with reconstruction is an option due to the chance on recurrence hypertrophy after breast reduction surgery. 
We describe the multidisciplinary approach in a 15 -yearold girl who presented with rapidly-growing tumors causing bilateral gigantomastia and her treatment.

\section{Case}

A 15-year-old girl was redirected to the department of surgery due to rapidly-growing breasts, which grew from zero volume to cup $\mathrm{G}$ in a short time. She had no relevant history of any disease, medication use, or previous surgery. Her family history of breast cancer and gigantomastia was negative. She had her first menstruation 1 month ago. There was no pregnancy. On physical examination, there was a disproportional breast size in comparison with the rest of her body and multiple solid tumors were palpable in both breasts. There were no pathologic enlarged lymph nodes palpable in both axilla. An endocrinologist was consulted for further screening. A blood test was performed, including cortisol, thyroid (TSH, FT4, and T3), estrogen, prolactin, progesterone, gonadotropins ( $\mathrm{LH}$,
FSH, and hCG/ beta-hCG), and ACTH. Also, tumor markers A1-fetoprotein and CA-125 were tested. No abnormalities were found.

\section{Imaging}

At first, both mammography and hormonal tests were performed. The breast lesions could not be accurately assessed on the mammography. Subsequently, magnetic resonance imaging (MRI) and ultrasound of the breasts were conducted. MRI showed multiple well-bounded masses in both breasts with varying intensity (Fig. 1). There were no signs of malignancy as the MRI was classified as BI-RADS category 2 by the radiologist, indicating a definitive benign finding.

\section{Histopathology}

Next, three histological biopsies were conducted based on the previous conducted magnetic resonance imaging (Fig. 2). Lesion 1, located medial and superior in the left breast,
Fig. 1 MRI showing lesions in both breasts in transverse $(\mathbf{1}, \mathbf{2}, \mathbf{3})$ and sagittal plane (4), and T1- (1, 3) and T2 (2, 4)-weighted images

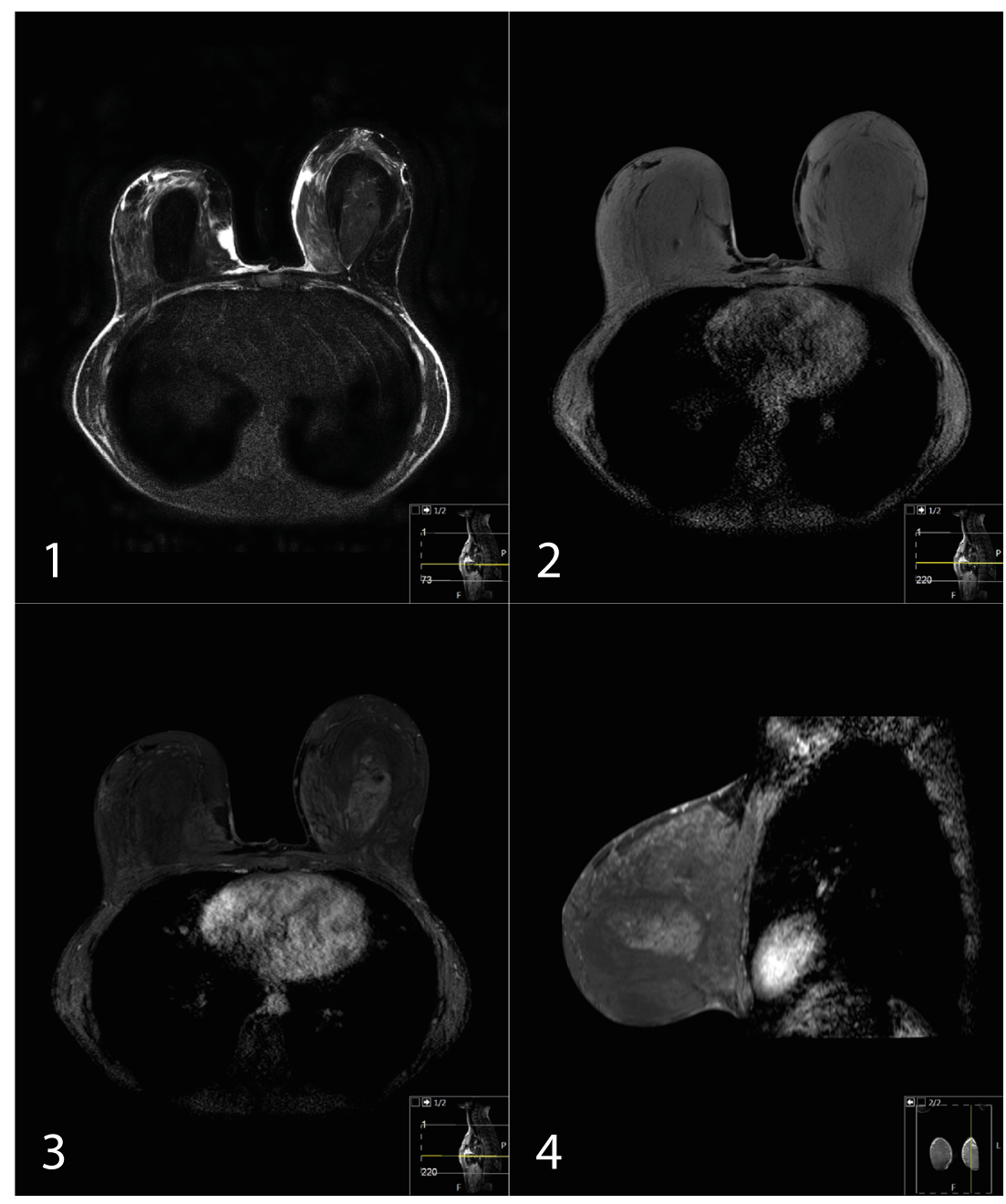




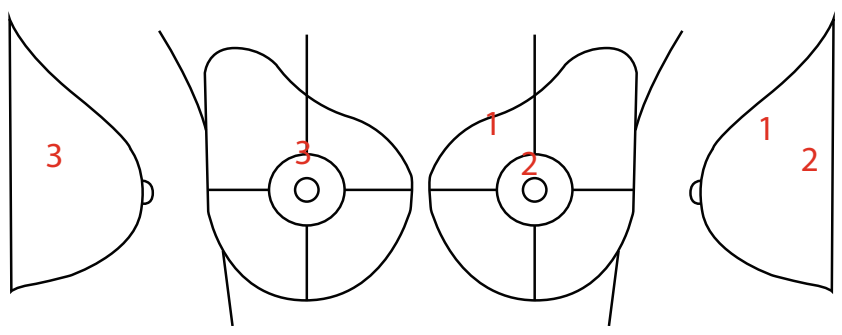

Fig. 2 Numbers indicating the locations of the lesions in both breasts of which histopathology was obtained by biopsy

showed fibrosis and ductal hyperplasia. Lesion 2, located central and superior in the left breast and with internal inhomogeneity on MRI, showed ductal hyperplasia with pseudoangiomatous stroma hyperplasia (PASH). Lesion 3, located central and superior in the right breast and with internal septae on MRI, also showed ductal hyperplasia with PASH.

\section{Treatment}

Surgical resection was not performed at this time. To monitor the growth of the lesions, a MRI every 6 months was done. No significant changes compared to the previous MRIs were seen. Two years later, the patient was directed to the department of plastic surgery asking for a breast reduction. She was 17-yearold and had multiple complaints, including neck and back pain, mastalgia, and unwanted attention at school. She stopped playing volleyball due to these complaints. During clinical examination (Fig. 3), both breasts were enlarged and multiple tumors were palpable in both breasts. Her skin was extremely thin and there was no subcutaneous fat layer. The left breast was larger than the right one. The patient had a very slender posture with a body weight of $54 \mathrm{~kg}$. She was $175-\mathrm{cm}$ tall, resulting in a body mass index of 17.6. She has breast cup $\mathrm{H}$, with an extent of $60 \mathrm{~cm}$. Her breasts have not grown compared with the year before. At this point, we estimated that the patient's breasts were over $1.5 \mathrm{~kg}$ ( $3 \%$ of her body weight), indicating gigantomastia. After being fully informed with the advantages and disadvantages, she opted for a breast reduction surgery.

Pre-operatively, another ultrasound of both breasts was conducted to confirm the locations of the lesions. In the left breast, well-bounded masses were seen retro-areolar and caudal, which had a similar aspect as a lipoma (Fig. 4). In the lateral side of the breast, a few similar but smaller masses were seen. In the right breast, a similar distribution was seen, but with slightly bigger masses. During surgery, the radiologist was present to provide ultrasound guidance in order to remove the lesions in toto.

The breast reduction was done according to the Wise pattern with a medial-cranial vascularization of the nippleareola complex. The procedure was started with the left breast. After the preparation from the inframammary fold (IMF) until the pectoralis major's fascia, the lesions were directly identified using ultrasound and palpation and subsequently separated from the glandular tissue. Four lesions were removed from the left breast. Two lesions (I and II) were located central in the superior part of the breast. One (III) of the lesion was located medially in the inferior part of the breast, which was fixed on the fascia of the $\mathrm{m}$. pectoralis and therefore difficult to release. Laterally (IV), a big lesion was removed causing less filling of the inferior part of the breast. A total of $381 \mathrm{~g}$ was removed from the left breast (Fig. 5). After closing the left breast, the same procedure and approach was done at the right side. In the right breast, three lesions were also detected by ultrasound and removed. The lesions were located centrocaudal (V), laterocaudal (VI), and centrocranial (VII).

A total of $324 \mathrm{~g}$ was removed from the smaller right breast. The surgery went without complications and the patient was dismissed from the hospital after 2 days. Given the age of the patient, a mastectomy was not desirable. We did not remove more tissue than the tumors itself. Therefore, the patients' breasts were still relatively large postoperatively (breast cup E, with an extent of $60 \mathrm{~cm}$ ) (Fig. 3). The skin was extremely loose and thin that excision of more breast tissue would have led to less projection
Fig. 3 Photo of both breasts preoperatively (left) and 1 year postoperatively (right)

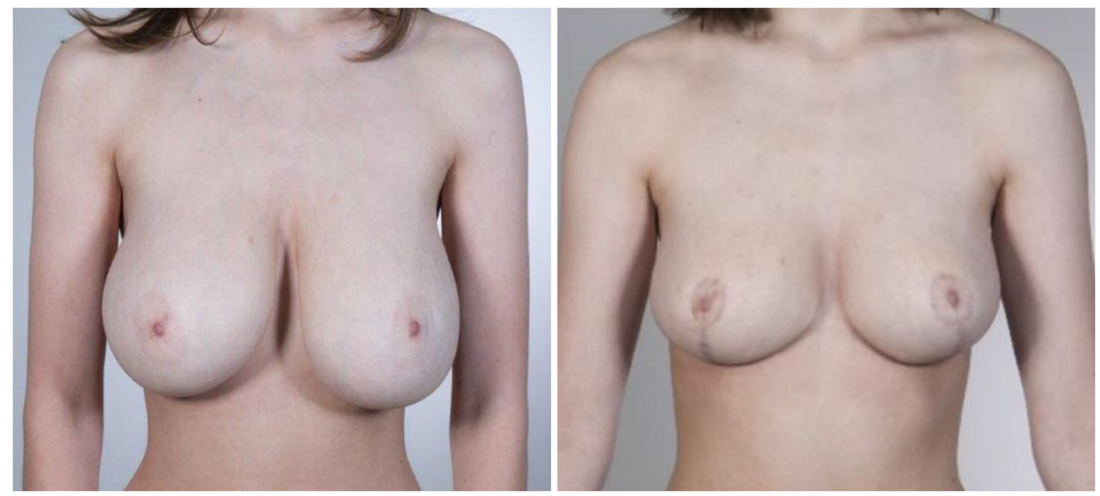



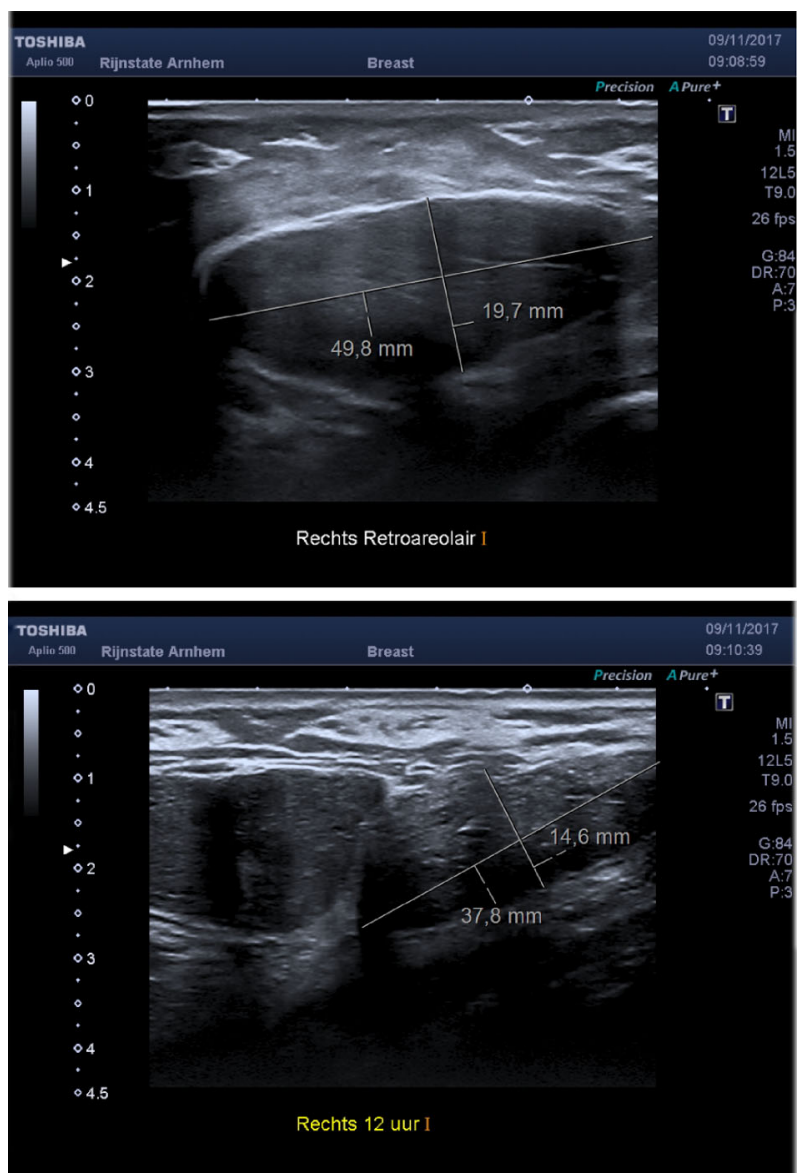

Fig. 4 Ultrasound, made pre-operatively, showing the aspects of two lesions with their measurements

of the breasts and thus a wrinkled skin. Also, in this case, a revision surgery is feasible in the future with acceptable cosmetic outcome, if required.
All seven lesions were sent for pathological evaluation. Histological examination showed glandular tissue conform age. Various amounts of PASH was seen and focal gynecomastia like ductal hyperplasia was found. This ductal hyperplasia in the breast is a proliferation of ductal epithelium with the histological features of (florid) gynecomastia. It should be regarded as a histological variant of benign ductal hyperplasia with typical three-layered ductal epithelium. No in situ carcinoma or malignancy was found.

\section{Follow-up}

In the first week of follow-up, there was a minor wound dehiscence which did not lead to any further problems. Although the breasts were still large, she was pleased with the result and observed less functional problems 4 months after surgery. One year after the surgery, she is happy with the size of her breasts and is not opting for further breast reduction surgery yet. The skin was retracted and the scars have healed well over time.

\section{Discussion}

We described our diagnostic workup and surgical treatment in a patient in which gigantomastia occurred at 15 years of age due to bilateral multiple benign (PASH) tumors. Tumorforming PASH is uncommon and usually presents as solid well-circumcised mass. Bilateral diffuse multiple tumors leading to massive bilateral breast enlargement are rare. Other reports have been published presenting patients with bilateral gigantomastia due to PASH [5-9], all reporting bilateral breast enlargement, with palpable masses in some cases. However,
Fig. 5 Pre-operative photos showing the bulging of the tumors in the left breast (upper) and the lipomatous aspect of one of the encapsulated tumors during excision (lower)

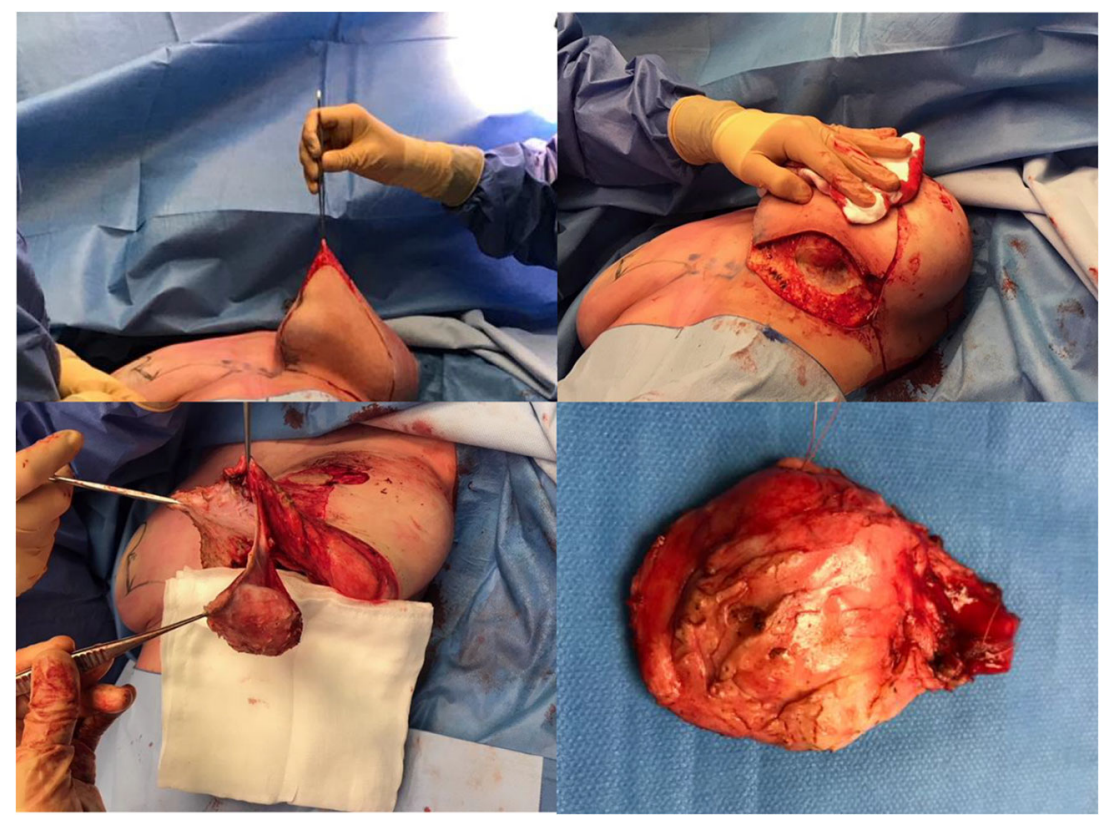


all these patients were between 29 and 46 years old which is in contrast to our adolescent patient. The exact etiology of PASH is unclear. The general accepted hypothesis is that stromal hyperplasia is the result of an atypical response to hormonal stimuli, with progesterone as main stimulus [4].

It is important to make histological distinction with a lowgrade angiosarcoma, since this requires invasive treatment, including wide excision and chemotherapy. Additionally, the differential diagnosis consists of mammary hamartoma, fibroadenoma, and myofibroblastoma. However, PASH is described as a benign entity; malignancy arising from a PASH nodule has been previously described [10]. PASH can co-exist with malignant processes within the breast.

There are no specific features to identify PASH in radiological appearance; however, common features of PASH have been described in the literature. On mammography, the most common appearance is a solid, non-calcified mass or localized increased stroma. On ultrasound, a well-defined and hypoechoic mass was most common [11]. In our case, both mammography and ultrasound were conducted. The ultrasound showed a similar aspect, while no evident abnormalities were observed in mammography.

In contrast with mammography and ultrasound, little has been reported on MRI characteristics. No common features have been described and the signal on both T1- and T2weighted images may vary [12]. A MRI is conducted in our patient to assess the lesions and determine their locations. In our case, well-bounded masses were seen with varying intensity.

In case of bilateral gigantomastia due to PASH, the surgical options consist of reduction mammoplasty and bilateral mastectomy (with reconstruction). The choice for either one is made based on the patient's preference. An important factor to inform the patient about is the chance on recurrence, which ranges from 0 up to $22 \%$ after excision $[4,13-15]$. This recurrent PASH is known to be benign but can grow rapidly and can be treated with re-excision. In our case, a breast reduction is performed. Until today, no recurrence has been observed during follow-up. In the other cases presenting patients with bilateral gigantomastia due to PASH, mastectomies were performed, except for two where in one patient a breast reduction was performed and in the other one the lesions were observed [5-9]. No recurrence was reported.

\section{Conclusion}

Gigantomastia due to rapidly-growing PASH tumors is rare. PASH has variable features on radiological imaging and therefore requires biopsy for diagnosis. Depending on the patient, surgery may be needed to relieve symptoms and prevent progression. Follow-up after excision in case of breast reduction surgery is recommended due to the chance on recurrence.
Funding There was no external funding for the study.

\section{Compliance with ethical standards}

Conflict of interest Maarten Vijverberg, Henriette Kroese-Deutman, Carla Meeuwis, and Robert Kornegoor declare they have no conflict of interest.

Ethical standards For this retrospective study, formal consent from a local ethics committee is not required.

Patient consent Patient provided consent prior to her inclusion in the study and for the use of her images.

Open Access This article is distributed under the terms of the Creative Commons Attribution 4.0 International License (http:// creativecommons.org/licenses/by/4.0/), which permits unrestricted use, distribution, and reproduction in any medium, provided you give appropriate credit to the original author(s) and the source, provide a link to the Creative Commons license, and indicate if changes were made.

\section{References}

1. Dancey A, Khan M, Dawson J, Peart F (2008) Gigantomastia-a classification and review of the literature. J Plast Reconstr Aesthet Surg 61(5):493-502

2. Dafydd H, Roehl KR, Phillips LG, Dancey A, Peart F, Shokrollahi K (2011) Redefining gigantomastia. J Plast Reconstr Aesthet Surg 64(2):160-163

3. Vuitch MF, Rosen PP, Erlandson RA (1986) Pseudoangiomatous hyperplasia of mammary stroma. Hum Pathol 17(2):185-191

4. Virk RK, Khan A (2010) Pseudoangiomatous stromal hyperplasia: an overview. Arch Pathol Lab Med 134(7):1070-1074

5. Alikhassi A, Ensani F, Omranipour R, Abdollahi A (2016) Bilateral simultaneous pseudoangiomatous stromal hyperplasia of the breasts and axillae: imaging findings with pathological and clinical correlation. Case Rep Radiol 9084820. https://doi.org/10.1155/ 2016/9084820

6. Krawczyk N, Fehm T, Ruckhaberle E, Mohrmann S, Riemer J, Braunstein S, Hoffmann J (2016) Bilateral diffuse pseudoangiomatous stromal hyperplasia (PASH) causing gigantomastia in a 33-year-old pregnant woman: case report. Breast Care (Basel) 11(5):356-358

7. Bourke AG, Tiang S, Harvey N, McClure R (2015) Pseudoangiomatous stromal hyperplasia causing massive breast enlargement. BMJ Case Rep. https://doi.org/10.1136/bcr-2014-204343

8. Oppenheimer AJ, Oppenheimer DC, Fiala TG, Noori S (2016) Pseudoangiomatous stromal hyperplasia: a rare cause of idiopathic gigantomastia. Plast Reconstr Surg Glob Open 4(1):e593

9. Roy M, Lee J, Aldekhayel S, Dionisopoulos T (2015) Pseudoangiomatous stromal hyperplasia: a rare cause of idiopathic gigantomastia. Plast Reconstr Surg Glob Open 3(9):e501

10. Nassar H, Elieff MP, Kronz JD, Argani P (2010) Pseudoangiomatous stromal hyperplasia (PASH) of the breast with foci of morphologic malignancy: a case of PASH with malignant transformation? Int J Surg Pathol 18(6):564-569

11. Celliers L, Wong DD, Bourke A (2010) Pseudoangiomatous stromal hyperplasia: a study of the mammographic and sonographic features. Clin Radiol 65(2):145-149

12. Solomou E, Kraniotis P, Patriarcheas G (2012) A case of a giant pseudoangiomatous stromal hyperplasia of the breast: magnetic resonance imaging findings. Rare Tumors 4(2):e23 
13. Powell CM, Cranor ML, Rosen PP (1995) Pseudoangiomatous stromal hyperplasia (PASH). A mammary stromal tumor with myofibroblastic differentiation. Am J Surg Pathol 19(3):270-277

14. Ferreira M, Albarracin CT, Resetkova E (2008) Pseudoangiomatous stromal hyperplasia tumor: a clinical, radiologic and pathologic study of 26 cases. Mod Pathol 21(2):201-207
15. Jones KN, Glazebrook KN, Reynolds C (2010) Pseudoangiomatous stromal hyperplasia: imaging findings with pathologic and clinical correlation. AJR Am J Roentgenol 195(4):1036-1042

Publisher's note Springer Nature remains neutral with regard to jurisdictional claims in published maps and institutional affiliations. 